\title{
Lecture: What Do We Expect from It?
}

DOI: $10.1134 / \mathrm{S} 1061934809080012$

The listener of a lecture carries away not so much particular knowledge as, perhaps, impressions. The memory bears original thoughts, vivid examples, historical facts and, of course, the lecturer's image. The student feels the caliber of the person; the absorption of the lecturer in the subject; his or her objectivity, competence, erudition in the broad sense; of great value are the manners and speech of the lecturer.

I remember lectures given by a relatively wellknown scientist, a corresponding member of the Academy of Sciences of the USSR, who spoke in an impassive gentle voice, and often wrote formulas, with his back to the audience and facing the board, for a long time. One had to strain to hear him. We can easily recollect lecturers who were impressive and expressive but almost recounted the textbook word-by-word. Of course, this is also useful: few students read the textbook before the lecture and the lecture will help them when they finally do read the textbook. However, it would be preferable for the lecturer to present (add) something of his/her own; textbooks gradually become outdated, and at least the accent or the examples used in lectures should change.

There are also some other extreme examples. One of our reputable analytical chemists believed that, in lectures, one has to speak about the facts not included in the textbooks. It seems to me that this is also wrong: in this case, the lectures will have no basic, no core, and the lecture will becomes a set of interesting and new, but scattered facts. The textbooks just present the basics. This is certainly true for the main, general courses.

We have sufficiently rigid curricula; it is considered that, in general, the lecture should cover all basic questions of the curriculum. This is, probably, true for the most general, basis courses; the special courses allow more freedom, differences in emphasis, different approaches to the presentation of the material, and variability in the choice of topics within the special course and even in the choice of special courses.

Experimentality disappears from lectures on analytical chemistry; this process is possibly irreversible, the more so, as modern facilities allow the lecturer to demonstrate a vast amount of material on the screen, especially using animation or video films.

The material of the lecture can be assimilated at the seminars; however, to ensure continuity and exclude contradictions, at least in the terms presented, the teachers holding seminars should attend the lectures.

Yu.A. Zolotov 